\title{
ARTIGO
}

\section{A TRADUÇÃO CULTURAL EM UMA VIDA EM SEGREDO}

\author{
Daniela de Azevedo \\ Universidade Estadual de Montes Claros - Unimontes, Brasil \\ dannyazef@yahoo.com.br \\ Osmar Pereira Oliva \\ Universidade Estadual de Montes Claros - Unimontes, Brasil \\ osmar.oliva@unimontes.br
}

DOI: https://doi.org/10.26512/caleidoscopio.v4i1.26682

Recebido em: 18/06/2019

Aceito em: 26/06/2020

Publicado em dezembro de 2020

RESUM0: Neste artigo, apresentamos uma análise comparada inédita da novela Uma vida em segredo (1964), de Autran Dourado, e sua tradução em língua inglesa, $A$ hidden life (1969), por Edgar H. Miller. Na busca de uma equivalência tradutória de aspectos estilísticos e culturais entre as narrativas, analisamos alguns excertos de $A$ hidden life no intuito de identificar as estratégias de tradução utilizadas por Miller e como elas (des)constroem a alteridade do texto-fonte. Concluímos que a alteridade foi preservada no texto de chegada, apesar das dificuldades enfrentadas pelo tradutor para manter alguns aspectos regionais muito específicos do textofonte. Evidenciamos a impossibilidade do uso de uma estratégia de tradução em detrimento de outras devido à complexidade da tradução literária, a qual requer conhecimento amplo e diversificado de técnicas de tradução, bem como do estilo narrativo do escritor e dos aspectos históricos e socioculturais que contextualizam a obra a ser traduzida.

Palavras-chave: Tradução literária, Tradução Cultural, Estratégias de tradução, Alteridade, Uma vida em segredo.

\section{CULTURAL TRANSLATION IN UMA VIDA EM SEGREDO}

\begin{abstract}
In this paper it is presented an unpublished comparative analysis of the novel Uma vida em segredo (1964) by Autran Dourado, and its English translation, $A$ hidden life (1969) by Edgar H. Miller. In the quest for an equivalence of stylistic and cultural aspects between the narratives, it was analyzed some excerpts of a Hidden Life in order to identify the translation strategies used by Miller, and how they (de)constructed the otherness of the source text. It was concluded that the otherness was preserved in the target text, despite the translation difficulties faced by the translator to keep some very specific regional aspects of the source text. It was evidenced the impossibility of using a translation strategy to the detriment of others due to the complexity of the literary translation, which requires a broad and
\end{abstract}


diversified knowledge of translation techniques, as well as the historical and sociocultural aspects which contextualize the work to be translated.

Keywords: Literary translation, Cultural translation, Translation strategies, Otherness, $A$ hidden life.

\section{Considerações Iniciais}

A tradução é uma das diversas formas da linguagem humana. Se reduzíssemos o seu conceito à forma mais primitiva de comunicação, poderíamos afirmar que todo ato comunicativo é também um ato tradutório, visto que tal ato, de acordo com Steiner (1975), pressupõe interpretação ativa por parte do receptor que, então, dá sentido à mensagem a partir do seu próprio universo linguístico e conceitual. Isso acontece porque, embora usemos as mesmas palavras numa dada língua, seus sentidos não estão estanques, muito menos seus usos, e assim cada indivíduo opera na língua um pequeno desvio do que seria seu suposto padrão. Tradução, nesse contexto, seria a interpretação dos atos comunicativos.

Contudo, o ato de traduzir não é tarefa simples e tampouco sua definição pode ser colocada de maneira tão resumida. Partindo da premissa de que a visão de mundo é transmitida por meio de uma determinada língua a partir da perspectiva cultural, social e política da comunidade que dela se serve como veículo de comunicação, a tradução, ou ainda a transposição de uma língua para outra, implica, indubitavelmente, a mudança de perspectiva, visto que a comunidade da língua de chegada compartilha de uma visão de mundo diferente. Some-se a isso o fato de que o próprio sistema linguístico, por mais próximas que as línguas sejam em suas origens, também sofre alterações.

A escolha entre a tradução ad verbum ${ }^{8}$ e ad sensum ${ }^{9}$ é a dicotomia colocada por vários teóricos dos estudos da tradução ao longo dos séculos, desde Cícero até a atualidade. Para exemplificar esse dilema, Nord (2006) cita alguns desses teóricos:

Cícero distinguiu entre traduzir "como um retórico" ou "como um tradutor". Martinho Lutero fez a distinção entre "Germanização" e "tradução". Schleiermacher falou sobre "levar o texto até o leitor" ou "levar o leitor até o texto". Eugene A. Nida e suas "equivalências funcional"

\footnotetext{
${ }^{8}$ Segundo a palavra.

${ }^{9}$ Segundo o sentido.
} 
e "dinâmica", ou ainda, Lawrence Venuti que estabeleceu a dicotomia "tradução domesticada" x "tradução estrangeirizada"10 (Tradução nossa).

A tradução, portanto, é um processo que envolve não somente a transposição de uma mensagem de uma língua para outra por meio de adequação do vocabulário e da estrutura gramatical, mas também a interpretação de um texto em uma língua de partida para uma língua de chegada, criando assim um novo texto. Tal interpretação depende da subjetividade do leitor/tradutor e de seu conhecimento sobre a cultura da língua de chegada.

Talvez o filósofo polonês Friedrich Daniel Ernst Schleiermacher, em "Sobre os diferentes métodos de tradução" (2010) ${ }^{11}$, tenha lançado luz sobre a questão ao afirmar que a tarefa do tradutor é fornecer ao seu leitor o mesmo sentimento, as mesmas emoções, as mesmas imagens e a mesma fruição que a obra original lhe proporcionou. Isso equivaleria dizer que o tradutor deve aproximar seu autor e seu leitor, propiciando ao último, no conforto da sua língua materna, uma compreensão correta e completa e o gozo do primeiro. Para tanto, na concepção de Schleiermacher, há dois caminhos para que esse intuito seja alcançado:

\footnotetext{
Ou bem o tradutor deixa o escritor o mais tranquilo possível e faz com que o leitor vá a seu encontro, ou bem deixa o mais tranquilo possível o leitor e faz com que o escritor vá a seu encontro. Ambos os caminhos são tão completamente diferentes que um deles tem que ser seguido com o maior rigor, pois qualquer mistura produz necessariamente um resultado muito insatisfatório, e é de temer-se que o encontro do escritor e do leitor falhe inteiramente (SCHLEIERMACHER, 2010, p. 57).
}

Na primeira hipótese, o tradutor se esforça para que o seu conhecimento da língua da obra original seja posto a serviço do leitor, levando-o a crer que a obra traduzida é original. 0 tradutor busca transmitir aos seus leitores as mesmas impressões que ele teve da obra enquanto leitor, guiando-os até o lugar que ele ocupa e que propriamente lhe é estranho, já que é o lugar do Outro. Essa seria a tradução estrangeirizante. Na segunda hipótese, Schleiermacher concebe a tradução

\footnotetext{
${ }^{10}$ Cicero, who distinguished between translating "like a rhetorician" or "like a translato". Martin Luther, who made a distinction between "Germanizing" and "translating". Schleiermacher, who spoke about "taking the text to the reader" or "taking the reader to the text". Eugene A. Nida's "functional" or "dynamic equivalence" vs. "formal equivalence", or Lawrence Venuti's "domesticating" vs. "foreignezing" translation (NORD, 2006, p. 141).

11 Ensaio escrito em 1813. Traduzido por Celso R. Braida em 2010.
} 
domesticadora: trata-se de uma tradução mais elaborada e exige muito mais habilidade do tradutor, pois ele passa a fazer o papel do autor; porém, um autor que, tendo conhecimento da língua para a qual a sua obra será traduzida, não precisa de um tradutor, passando a ser ele mesmo o autor e tradutor do seu texto, ou seja, ele traduz um autor como se esse mesmo autor tivesse escrito na língua de chegada. Schleiermacher afirma que não há como ficar no meio termo das duas hipóteses, já que isso resultaria em uma tradução pouco confiável.

Britto (2010) critica o tradutor alemão por ter concebido hipóteses tão absolutistas, e declara:

\begin{abstract}
Na verdade, a própria ideia de que seria possível fazer uma tradução totalmente domesticadora ou totalmente estrangeirizante não pode ser levada a sério. Pois uma tradução totalmente domesticadora seria na verdade algo que não é mais uma tradução: isto é, uma adaptação. Por outro lado, é difícil imaginar o que seria uma tradução totalmente estrangeirizante (BRITTO, 2010, p. 136).
\end{abstract}

Nas hipóteses colocadas Schleiermacher, enxergamos mais um paradoxo: ele acreditava que para cumprir o objetivo da tradução, deveria haver uma estranheza de natureza gramatical, semântica ou estética. Por estranheza, entendemos vestígios da língua e da cultura do texto original, o que foge, portanto, do que ele postulou em suas hipóteses.

Mais tarde, Venuti (1995), em seus estudos sobre tradução, revalida as noções de tradução domesticadora e tradução estrangeirizante elaboradas por Schleiermacher. A domesticação busca valorizar a cultura do texto de chegada em detrimento da cultura do texto-fonte, escondendo, segundo o autor, as diferenças linguísticas e da cultura estrangeira, e mascarando a violência etnocêntrica desse tipo de tradução, pois se inscreve no texto traduzido uma interpretação parcial, baseada em valores da cultura alvo, não considerando, portanto, a alteridade do texto-fonte. Assim, Venuti defende a estrangeirização como uma forma de valorizar os elementos culturais presentes no texto-fonte, mantendo-os no texto de chegada, ou seja, o tradutor deveria preservar os elementos que causam estranheza na cultura alvo.

Britto (2010) afirma que quanto maior o grau de proximidade entre as culturas, menos problemática é a escolha do tradutor. Ele apresenta, como exemplo, 
a tradução de um texto literário argentino para o português do Brasil, dizendo que, neste caso, a proximidade entre as línguas de partida e de chegada e a proximidade geográfica entre os países onde essas línguas são faladas fazem com que haja poucas diferenças entre os resultados de uma abordagem mais domesticadora e uma mais estrangeirizante. Na primeira abordagem, todos os termos seriam aportuguesados, por exemplo. Em uma abordagem mais estrangeirizante, boa parte do vocabulário relativo às coisas da Argentina seria mantida em espanhol, pois, provavelmente, isso não seria um obstáculo para um leitor brasileiro medianamente culto.

No outro extremo, Britto (2010) explica que teríamos a tradução para o português brasileiro de uma obra muito antiga, escrita em uma língua bem distante da nossa, por uma civilização sobre a qual muito pouco se conhece. Esse é o caso da tradução de um antigo poema épico mesopotâmico - Gilgamesh ${ }^{12}$ - considerado a obra literária mais antiga da humanidade:

\begin{abstract}
Nesse caso, a distância entre a cultura-fonte e a cultura-meta é tamanha que as categorias de uma dificilmente poderiam ser convertidas nas da outra, e a diferença entre as duas abordagens resultaria em dois empreendimentos radicalmente diversos. A opção domesticadora forçosamente geraria um texto que não seria uma tradução, e sim uma adaptação da obra original, transplantando as aventuras de Gilgamesh para a mata amazônica, por exemplo; já a escolha da alternativa estrangeirizante tornaria necessária a elaboração de um rico aparato paratextual - um texto introdutório contendo informações contextualizadoras, notas do tradutor extensas e abundantes. Foi a opção estrangeirizante, aliás, a adotada por Maysa Monção Gabrielli, a tradutora brasileira do Gilgamesh (BRITTO, 2010, p. 136-137).
\end{abstract}

Britto (2010) explica que a maioria das traduções fica entre esses dois extremos. Isso quer dizer que, quase sempre, o tradutor domestica mais o original na medida em que o texto se destina a um leitor do qual se pode exigir pouco, um leitor que tem pouco conhecimento ou acesso à cultura do texto original. Em

\footnotetext{
${ }^{12}$ A Epopeia de Gilgamesh, escrita pelos sumérios em torno de 2000 a. c., é um poema que narra os feitos de Gilgamesh, rei de Uruk, em sua procura pela imortalidade. 0 trabalho de tradução da obra foi realizado por Henry Rawlinson e George Smith na segunda metade do século XIX, e só foi possível graças às inscrições de Dario, rei Persa, que transcrevia caracteres cuneiformes para três idiomas: persa, babilônio e elamita. Esse trabalho foi ampliado quando novos trechos da narrativa foram encontrados posteriormente. Fonte: Brasil Escola. Disponível em: <https://brasilescola.uol.com.br/o-que-e/historia/o-que-e-epopeia-gilgamesh.htm>. Acesso em: 5 ago. 2018.
} 
situação inversa, o tradutor pode produzir um texto mais estrangeirizado, pressupondo que o leitor não terá dificuldades para transportar-se para outra cultura. Esse seria o caso, por exemplo, de obras de autores norte-americanos traduzidas para leitores brasileiros. Dada a grande influência da cultura norteamericana no Brasil, seria viável esse tipo de tradução. 0 contrário, no entanto, já não é tão evidente. Assim, a tradução de uma obra brasileira para o leitor norteamericano exigiria que o tradutor percorresse o caminho da domesticação, caminho esse que pode ser difícil para o tradutor, dependendo do seu grau de intimidade com a cultura brasileira.

É exatamente esse o caso das narrativas que são objetos de nossa pesquisa. A ambientação de Uma vida em segredo em Minas Gerais estabelece uma ponte, uma relação entre o mundo real - interior de Minas Gerais - e o mundo ficcional, entre a realidade e a imaginação. 0 universo regional, típico do interior de Minas Gerais se distancia do contexto norte-americano, não somente geográfico, mas principalmente cultural e linguístico. Sendo assim, como transportar o leitor norteamericano para o mundo real da ficção, o interior de Minas Gerais? É o que buscaremos entender a partir da próxima seção.

\section{Tradução, alteridade e cultura}

Antes de iniciarmos a análise, esclarecemos que ela é apenas uma parte da pesquisa apresentada em dissertação de mestrado na área de estudos literários. ${ }^{13}$

Para o melhor entendimento das estratégias utilizadas por Edgar Miller na tradução de Uma vida em segredo, consideramos importante a proposição de Aixelá (2013) sobre tradução literária e a transposição dos aspectos culturais nela envolvidos.

Aixelá pontua questões primordiais sobre a tradução e suas relações com a linguagem, com a noção do Outro e com as culturas envolvidas no processo:

Se há uma coisa que se pode afirmar sem nenhuma dúvida sobre tradução é a sua historicidade, que caminha junto à noção de linguagem e à noção do outro que cada comunidade linguística tem tido ao longo de sua

\footnotetext{
13 Mestrado em Estudos Literários, Universidade Estadual de Montes Claros. Dissertação intitulada
} “Aspectos da tradução em língua inglesa de Uma vida em Segredo", defendida em abril de 2019. 
existência. 0 fato de que em qualquer caso e em qualquer momento a tradução mistura duas ou mais culturas (não podemos esquecer o fenômeno, bastante comum, das traduções mediadas ou de segunda mão, como as traduções de traduções), implica em um equilíbrio instável de poder, um equilíbrio que dependerá em grande parte do peso relativo da cultura exportadora e de como ela é sentida na cultura receptora. Tratase da cultura em que a língua do texto alvo é quase sempre elaborada e, portanto, a que geralmente toma as decisões sobre o modo como uma tradução é feita (começando com a decisão de se traduzir ou não um texto) (AIXELÁ, 2013, p. 186).

De acordo com o autor, a tradução literária atua sobre quatro campos básicos de diversidade entre dois sistemas linguísticos: o linguístico, o interpretativo, o pragmático e o cultural. Os itens culturais específicos correspondem à área mais arbitrária de cada sistema linguístico e apresentam, portanto, os maiores desafios dentro do processo de transferência cultural na tradução. Esses itens se referem a hábitos, valores e sistemas classificatórios típicos de uma cultura, que podem ser iguais ou diferentes em outro segmento cultural. Outros itens, menos específicos, como nomes de pessoas, de lugares, instituições e sistemas de medidas são mais facilmente identificáveis e reconhecidos como itens culturais. No entanto, há itens culturais que só podem ser percebidos a partir de conflitos resultantes do processo de transferência, quando há discrepância ou incompatibilidade entre os sistemas de valores nas culturas envolvidas no processo de tradução, ou seja, o estranhamento.

Considerando as reflexões de Venuti (1995) e Aixelá (2013), analisamos alguns excertos de $A$ hidden life, focando nas estratégias utilizadas pelo tradutor, no intuito de perceber como ele trabalhou a questão da alteridade, preservando aspectos culturais do contexto de Uma vida em segredo, presentes em vocabulário específico utilizado por Autran Dourado. Dividimos a análise em duas partes: a primeira, considerando situações em que o tradutor preservou o termo em língua portuguesa; a segunda, uma situação em que ele verteu o termo para a língua inglesa.

Para a primeira parte da análise, utilizamos o quadro abaixo para facilitar a visualização do leitor dos trechos em português e em inglês: 


\begin{tabular}{|c|c|}
\hline Uma vida em segredo & A hidden life \\
\hline $\begin{array}{l}\text { Ficou para sempre reinando sozinho no } \\
\text { território do Fundão (DOURADO, 2010, p. 19). }\end{array}$ & $\begin{array}{l}\text { He stayed there reigning alone over the } \\
\text { territory of Fundão (DOURADO, 1969, p. 6). }\end{array}$ \\
\hline $\begin{array}{l}0 \text { jeito era mandá-la para Barbacena }[\ldots] \\
\text { (DOURADO, 2010, p. 25). }\end{array}$ & $\begin{array}{l}\text { The thing to do was to send her to Barbacena } \\
{[\ldots] \text { (DOURADO, 1969, p. 15). }}\end{array}$ \\
\hline $\begin{array}{l}\text { Só sabia metade da ave-maria (DOURADO, 2010, } \\
\text { p. 33). }\end{array}$ & $\begin{array}{l}\text { She knew only half of the "Ave Maria" } \\
\text { (DOURADO, 1969, p. 27). }\end{array}$ \\
\hline $\begin{array}{llll}\text { Aprendera muito no } & \text { colégio de dona } \\
\text { Mariquinha Menezes, } & \text { em Ouro } & \text { Preto } \\
\text { (DOURADO, 2010, p. 38). } & & & \end{array}$ & $\begin{array}{l}\text { She had learned a great deal at Dona } \\
\text { Mariquinha Menezes's school in Ouro Preto } \\
\text { (DOURAD0, 1969, p. 34). }\end{array}$ \\
\hline $\begin{array}{l}\text { Só se lembrava de balbúrdia assim nas festas de } \\
\text { mutirão, espectadora (DOURADO, 2010, p. 40). }\end{array}$ & $\begin{array}{l}\text { She remembered such bedlam only as a } \\
\text { spectator at the feasts of mutirão (DOURADO, } \\
1969 \text {, p. 37, grifo do tradutor). }\end{array}$ \\
\hline
\end{tabular}

Fonte: a autora.

Percebemos, por meio desses excertos, que Miller optou pela manutenção dos nomes próprios - item menos específico (AIXELÁ, 2013), e da expressão Ave Maria, do pronome de tratamento informal "dona" e do termo "mutirão" - itens mais específicos (AIXELÁ, 2013).

A não tradução da expressão Ave Maria causou-nos estranheza, visto que há a expressão correspondente em inglês - Hail Mary, o que facilitaria a compreensão do leitor. Questionamos Miller ${ }^{14}$ sobre a manutenção do termo em português e ele explicou que: “Ave Maria não é português, mas latim, sendo [uma expressão] muito usada em inglês, especialmente antes de a Igreja Católica permitir o uso da língua vernacular no ritual da igreja"15 (Tradução nossa).

Como a cultura americana se assemelha à brasileira nesse aspecto religioso, Miller preserva o contexto histórico da obra, visto que no início do século XX, os rituais da Igreja Católica ainda eram em latim. Assim, "Ave Maria", seguindo o proposto por Aixelá (2013) torna-se item menos específico no contexto analisado, o que, obviamente, seria diferente se tivéssemos a tradução da novela para uma cultura totalmente adversa, como a indiana, por exemplo.

\footnotetext{
${ }^{14}$ Em entrevista concedida a pesquisadora em agosto de 2016.

15 Ave Maria is, of course, not Portuguese but Latin and is widely used in English, particularly before the Catholic Church allowed the use of the vernacular in church ritual (MILLER, 2018).
} 
Também nos causou estranheza a manutenção do pronome de tratamento “dona”. De acordo com Miller (2018), como não há um termo correspondente em língua inglesa, a exemplo de outros tradutores que trabalharam com literatura brasileira na mesma época, ele optou por deixar o termo em português, e cita o exemplo de Dona Flor e seus dois maridos, de Jorge Amado - Dona Flor and her two husbands, em inglês. Sobre a manutenção da palavra "mutirão", que se encaixa no mesmo caso da palavra "dona”, Miller explicou que a tradução foi feita há quase cinquenta anos e não se lembra do contexto em que a palavra "mutirão" foi usada, e, ainda, que não consegue pensar em um termo específico em língua inglesa.

Nesses dois casos, acreditamos que estrangeirização pode ter prejudicado, parcialmente, a interpretação do leitor. O pronome "Dona" pode ter sido percebido como nome próprio, pois está sempre grafado com inicial maiúscula e sem itálico, como pode ser comprovado por meio de outro trecho da narrativa:

Sim senhora, dona Constança, disse o velho (DOURADO, 2010, p. 38).

“Well, well, Dona Constança," the old priest said (DOURADO, 1969, p. 35).

Já a palavra "mutirão", grafada em itálico (veja quadro acima), leva o leitor, automaticamente, a duas inferências: é uma palavra estrangeira e que está ligada a algum tipo de festividade, visto que ela é antecedida da palavra feasts; porém, nem sempre um mutirão pressupõe uma festa. A adição de uma explicação tornaria o termo mais claro para o leitor, como aconteceu com "garapa", também grafada em itálico. Na impossibilidade de traduzir essa palavra, Miller adiciona uma oração apositiva, tornando o seu sentido mais claro para o leitor:

Seu Chico Branco dava-lhe sempre um copo de garapa, [...] (DOURADO, 2010, p. 93).

Mr. Chico Branco always gave her a glass of garapa, a drink made of sugar cane (DOURADO, 1969, p. 119). 
Contudo, como a ocorrência dessas palavras na novela é irrelevante, a alteridade do texto-fonte é preservada.

Nos exemplos analisados, excetuando-se "Ave Maria”, é perceptível que Miller optou pela estrangeirização que, para Venuti (1995) e Britto (2010), é o caminho que mais respeita a identidade cultural e a fidelidade ao autor, permitindo ao tradutor agir como mediador cultural e não como protetor da pureza de sua cultura, respeitando a premissa de que as culturas podem interagir sem que uma seja engolida pela outra. Portanto, a estrangeirização teria a seu favor o fato de que é um processo tradutório ético, que respeita a língua e a cultura do Outro (BERMAN, 2007).

Outro conceito necessário para prosseguirmos na análise do processo de tradução de Uma vida em segredo, sob a ótica cultural, é a traduzibilidade. Iser (1996) alerta para a necessidade da perspectiva intercultural em contraposição ao simples comparativismo, pois a análise comparatista pode levar às superposições de culturas, gerando noções de hierarquia. Para ele, considerar as diferenças culturais é reconhecer o outro como tal, em sua alteridade, colocando em prática o potencial da traduzibilidade, que seria a técnica de modificar o texto-fonte de forma a torná-lo compreensível para o leitor que está inserido em uma cultura diferente. A traduzibilidade é "um conceito essencial para a compreensão dos encontros entre culturas e interações dentro das culturas. Nessa perspectiva, a traduzibilidade implica a tradução da alteridade, sem submetê-la a conceitos preconcebidos"16 (Tradução nossa).

Levando em consideração o conceito de traduzibilidade, na segunda parte da análise proposta, percebemos que Miller não seguiu de forma rígida o caminho da estrangeirização, pois ele buscou na língua inglesa, por vezes, palavras que poderiam levar o seu leitor a entender melhor do que se trata o termo correspondente em língua portuguesa e que não existe na língua inglesa. É o caso da palavra "monjolo", que é traduzida como mill wheel - roda d'água, em português. Ao optar por substituir "monjolo" por mill wheel, o tradutor trilha o caminho da domesticação, provavelmente para dar ao leitor uma ideia do cenário que sempre é

\footnotetext{
${ }^{16} \mathrm{~A}$ key concept for understanding encounters between cultures and interactions within cultures. In this view, translatability implies translation of otherness without subsuming it under preconceived notions (ISER, 1996, p. 9).
} 
rememorado por Biela, e por ser o monjolo um objeto de lembrança recorrente em toda a novela.

Quando perguntamos para Miller sobre a tradução de "monjolo", ele disse que teve muita dificuldade para encontrar um termo que representasse o objeto em língua inglesa, pois não sabia do que se tratava:

\begin{abstract}
Monjolo foi a palavra que nos deu mais trabalho. Nunca tínhamos ouvido falar de tal coisa, e não conseguimos encontrar o seu significado em nenhum dicionário de português (isso foi muito antes da facilidade da Internet e do Google Tradutor; é interessante notar que a tradução do Google dá a palavra em inglês como "macaco"). Finalmente, encontramos um mineiro na embaixada brasileira em Washington, que descreveu o que era um monjolo. Agora que já vi um, percebo que "roda d'água", provavelmente, não foi uma boa tradução. Mas eu não acho que isso tenha prejudicado a história, já que eu não conheço nenhum objeto similar no contexto cultural de língua inglesa ${ }^{17}$ (Tradução nossa).
\end{abstract}

A estratégia utilizada por Miller remete à proposição de Nascimento (2014) de que a tradução é um ato de invenção ou de reinvenção, ou ainda transcriação, como proposto por Campos (2006), o qual se assemelha a um perpétuo canteiro de obras, para onde se pode sempre retornar para rever, refazer, repropor. Assim, traduzir é "retraduzir, ver e rever o percurso da leitura-tradução de um texto, como ato de memória do primeiro contato com a obra e a língua do outro, as primeiras tentativas, os primeiros passos e os primeiros impasses nas sendas da tradução" (NASCIMENTO, 2014, p. 121).

Retomando a análise, inferimos que ao verter a palavra "monjolo", que é impregnada de valor denotativo, mas, principalmente, conotativo, e levando em consideração o contexto e o número de ocorrências da palavra, o tradutor assumiu o risco de que sua tradução suscitasse na mente do seu leitor uma imagem muito diferente daquela do texto original. Esse risco assumido pode ter gerado diferentes interpretações pelo leitor em língua inglesa, divergentes daquela pretendida por Autran Dourado, mas não necessariamente negativas. A tradução de "monjolo"

\footnotetext{
${ }^{17}$ Monjolo was the word that gave us the most difficulty. Neither of us had ever heard of such a thing and we could not find it in any Portuguese dictionary available to us (this was long before the facility of the Internet and Google Translation; it's interesting to note that Google Translation gives the word in English as "monkey"). We finally found a Mineiro at the Brazilian Embassy in Washington who described to us what a monjolo was. Now that I have seen one, I realize that "mill wheel" probably was not a good translation. But I don't think it detracted from the story since I don't know of any similar type of grist mill in the English-speaking world (MILLER, 2018).
} 
como mill wheel, poderia levar o leitor de $A$ hidden life a perder a sonoridade que o monjolo produz e, consequentemente, ele deixaria de compreender a memória musical que Biela nos apresenta, ao falar da Fazenda do Fundão. No entanto, como podemos comprovar no trecho transcrito abaixo, o emprego de outras palavras, em língua inglesa, que também exprimem musicalidade por remeterem aos sons da natureza, e ao próprio barulho produzido pelo monjolo, sobrepõe o emprego de mill wheel:

\begin{abstract}
Quando se punha a ouvir o riachinho correndo vagaroso numa plangência monótona, distante na noite. A água desviada do riacho corria numa canaleta até cair do alto no cocho do monjolo, que vergava rangente, e ela cuidava ouvir a batida fofa ou dura do pilão (DOURADO, 2010, p. 44).
\end{abstract}

\begin{abstract}
She could hear the little stream running slowly in a monotonous plaintiveness in the distance of the night, its water diverted from its banks into a little channel until it splashed from above into the bucket of the mill wheel that groaned and squeaked, and she thought she could hear the slap of the mill stone (DOURADO, 1969, p. 44, grifos nossos).
\end{abstract}

Em $A$ hidden life, por meio de onomatopeias, Miller conserva a musicalidade das lembranças de cousin Biela: splash ${ }^{18}$ remete ao barulho de água caindo; groan $^{19}$ e squeak ${ }^{20}$ representam o ranger do monjolo. Já slap ${ }^{21}$, também utilizada por Miller como onomatopeia, pela sua sonoridade, agrega valor conotativo de batida ao trecho analisado. Interessante notar que o tradutor, neste excerto, deu mais ênfase ao som produzido pelo monjolo que o próprio autor.

Provavelmente, Miller fez conexões da vida no campo de Biela com a sua, pois ele nasceu e foi criado em um estado do sudeste americano, reconhecido pela sua agricultura e música de raiz, e estereotipado como um dos estados mais caipiras dos Estados Unidos. Miller nos disse que "embora Dourado tenha escrito sobre a vida no seu Estado, Minas Gerais [...], a narrativa frequentemente me trazia memórias do meu Estado de origem, o Tennessee"22 (Tradução nossa).

\footnotetext{
18 Respingo; salpico; borrifo.

19 Gemido.

${ }^{20}$ Rangido.

21 Tapa.

${ }^{22}$ Even though Dourado wrote about life in his home state of Minas Gerais, [...] I was often reminded in his writing of my own home state of Tennessee (MILLER, 2018).
} 
Essa hipótese é fundamentada nos estudos de Schafer (1977) sobre a relação do homem com os sons da natureza. Schafer explica que os sons fundamentais de uma paisagem não precisam ser ouvidos conscientemente. Esses sons são aqueles criados pela geografia e pelo clima, como água, vento, planícies, pássaros, insetos e animais, podendo encerrar um significado arquetípico, uma vez que eles podem ficar tão profundamente impregnados nas pessoas que a vida sem eles seria sentida como um empobrecimento, afetando, assim, o comportamento e o estilo de vida de uma sociedade. Biela, privada dos sons que embalaram a sua infância, recorre às suas lembranças e lá se refugia. Ao identificar-se com o mundo de Biela, Miller preserva uma das características mais importantes da novela - a musicalidade. E é nessa identificação com as paisagens sonoras do interior de Minas Gerais que o tradutor consubstancia o configurar-se amorosamente na própria língua (CAMPOS, 2006), ou seja, foi pelo reconhecimento do Outro em si mesmo que Miller pôde ser fiel, neste aspecto, ao projeto literário de Autran Dourado em Uma vida em segredo.

Dessa forma, fidelidade e ética estão intimamente ligadas no processo de tradução de Uma vida em segredo, indo ao encontro da proposta de Berman (2002; 2007) de uma ética positiva na tradução, aquela que respeita e que acolhe o Outro, que reconhece e recebe o Outro enquanto Outro. A essa relação com o Outro, Berman denomina de visada ética da tradução: "abrir no nível da escritura uma certa relação com o Outro, fecundar o Próprio pela mediação do estrangeiro" (BERMAN, 2002, p. 16). Porém, essa escrita não é nada fácil, pois confronta com a estrutura etnocêntrica de qualquer cultura, que seria o desejo de ser um "todo puro e não misturado" (BERMAN, 2002, p. 16). O autor denomina esse fenômeno de visada cultural, e na sua concepção, a visada ética produz traduções de boa qualidade e a visada cultural traduções de má qualidade. As consequências da contradição entre a visada redutora da cultura e a visada ética do ato tradutório seriam:

Por um lado, ela se submete a essa injunção apropriadora e reprodutora, constitui-se como um de seus agentes. 0 que acaba por produzir traduções etnocêntricas, ou o que podemos chamar de "má" tradução. Mas, por outro lado, a visada ética do traduzir opõe-se por natureza a essa injunção: a essência da tradução é ser abertura, diálogo, mestiçagem, descentralização. Ela é relação ou não é nada (BERMAN, 2002, p. 17). 
A partir do enunciado de Berman, pode-se dizer que a busca pelo equilíbrio entre visada ética e cultural ameaça a aparente estabilidade das identidades. Inserido em uma cultura e contexto diferentes do autor, o tradutor depara-se com o dilema: forçar a sua língua a se lastrar de estranheza ou forçar a outra língua a se comportar como sua língua materna. "Ele quer ser escritor, mas não é senão reescritor. Ele é autor - e nunca o Autor. Sua obra de tradutor é uma obra, mas não é A Obra" (BERMAN, 2002, p. 20).

A resistência à cultura do Outro acarreta na deformação da tradução nos níveis linguístico e literário, e o acolhimento dessa mesma cultura é trair a sua própria identidade. Assim, o tradutor está sempre no limiar da fidelidade e da traição. “Traduzir, escrevia Franz Rosenzweig, 'é servir a dois senhores'. Tal é a metáfora ancilar. Trata-se de servir à obra, ao autor, à língua estrangeira (primeiro senhor) e de servir ao público e à língua própria (segundo senhor)" (BERMAN, 2002, p. 15). Ao servir ao primeiro senhor, o tradutor pode ser visto como um traidor, um estrangeiro; ao servir ao segundo, ele pode ser visto como um mal tradutor, pois se afasta daquilo que é a essência da tradução.

Portanto, um tradutor que não se envolve com a cultura do Outro terá dificuldades em desempenhar o seu papel, e estará colocando a sua competência à prova. Língua e cultura constituem o cerne da tradução. A apropriação de uma língua estrangeira é uma experiência densa e profunda, pois pressupõe a apropriação de sentidos, estes intimamente ligados à cultura.

Assim como a linguagem, a cultura é um código simbólico por meio do qual as mensagens são transmitidas e interpretadas. No entanto, a cultura vai além, por ser uma combinação de fatos históricos, sociais, geográficos, étnicos e outros mais. Por tudo isso, ao pensar em fazer um trabalho de tradução, o tradutor não deve levar em conta somente a transposição da palavra, a equivalência de significado, mas sim, os sentidos, o(s) contexto(s), o cenário a ser traduzido.

$\mathrm{Na}$ impossibilidade de uma equivalência completa entre o conjunto dos códigos de duas culturas diferentes, a tradução consiste em uma tentativa de decifração do sentido por meio da procura de aproximações entre culturas. No entanto, a tradução deve sempre focar no leitor da cultura de chegada da obra traduzida. 0 tradutor deve respeitar a obra original de forma que a versão traduzida 
corresponda ao original, mas sem ser de todo estranha para o leitor. Bassnett exemplifica:

O conceito de Deus Pai não pode ser traduzido para uma cultura onde a divindade é feminina. Tentar impor os valores culturais da língua fonte para a cultura da língua de chegada é terreno perigoso, [...]. 0 tradutor não pode ser o autor do texto-fonte, mas como autor do texto traduzido ele tem uma clara responsabilidade moral para com os seus leitores ${ }^{23}$ (Tradução nossa).

Por meio da proposição de Bassnett, notamos que a estratégia de equivalência é utilizada em $A$ hidden life no intuito de respeitar o leitor do texto de chegada, cuja cultura diverge da apresentada no contexto da obra aqui estudada. Nessa estratégia, “O termo utilizado na língua fonte é substituído por um equivalente na língua de chegada, servindo ao mesmo propósito na cultura da língua de chegada, sendo que o processo envolve a substituição de um signo da língua-fonte por um signo da língua de chegada"24 (Tradução nossa). Em Uma vida em segredo, este é o caso da palavra "monjolo". 0 tradutor buscou, na língua inglesa, uma palavra que remetesse o seu leitor o mais próximo possível à ideia de monjolo - mill wheel - uma vez que tal objeto não existe na cultura norte-americana.

É provável que se o tradutor tivesse optado pela permanência do termo em português, ele criaria um obstáculo para a compreensão do leitor da obra em inglês, principalmente pelo fato de que o monjolo é recorrente no decorrer da novela, por ser um dos objetos que remete Biela ao seu passado, na Fazenda do Fundão, como já citado. Dessa forma, ao traduzir o termo por um cujo signo remete ao significado de "monjolo", o tradutor preserva um aspecto importante de Uma vida em segredo, ou seja, mais uma vez, a alteridade do texto-fonte é preservada.

\footnotetext{
23 The concept of God the Father cannot be translated into a language where the deity is female. To attempt to impose the value system of the SL culture onto the TL culture is dangerous ground, [...]. The translator cannot be the author of the SL text, but as the author of the TL text has a clear moral responsibility to the TL readers (BASSNETT, 2002, p. 31-32).

24 The SL phrase is replaced by a TL phrase that serves the same purpose in the TL culture, and the process here involves the substitution of SL sign for TL sign (BASSNETT, 2002, p. 33).
} 


\section{Considerações Finais}

Embora a atividade tradutória seja muito antiga, e apesar da larga disparidade de épocas e contextos, as discussões sobre o tema persistem. A elaboração de teorizações sistematizadas e, em especial, a consolidação dos Estudos da Tradução como área acadêmica constituem fenômenos bastante recentes. Hoje, os estudos de tradução são feitos, também, com base na linguística, e buscam uma consistência teórica, por meio de diferentes abordagens, para questões como a traduzibilidade de fenômenos linguísticos e culturais; a influência que o texto de chegada recebe do tradutor enquanto leitor, na sua dimensão interpretativa; a originalidade do texto traduzido e, não menos importante, como a alteridade se materializa por meio da transculturalidade.

Finalizamos este artigo abordando dois pontos analisados por Costa (2012) sobre o processo tradutório: o deslocamento e o desenraizamento. Costa enfatiza o posicionamento de Bassnett (2002) a respeito da transculturalidade da tradução, afirmando que o ato tradutório vai além da mera transferência de significados de uma língua para outra, pois quando nos comunicamos

\footnotetext{
estamos sempre já engajadas na tradução, tanto para nós mesmas/os quanto para a/o outra/o. Se falar já implica traduzir e se a tradução é um processo de abertura à/ao outra/o, nele a identidade e a alteridade se misturam, tornando o ato tradutório um processo de deslocamento. $\mathrm{Na}$ tradução, há a obrigação moral e política de nos desenraizarmos, de vivermos, mesmo que temporariamente, sem teto para que a/o outra/o possa habitar, também provisoriamente, nossos lugares. Traduzir significa ir e vir [...] estar no entrelugar, na zona de contato, ou na fronteira Significa, enfim, existir sempre des-locada/o (COSTA, 2004, p. 44).
}

Em $A$ hidden life o tradutor, na maioria das vezes, desapega-se da sua cultura. Seu deslocamento, respeitando a alteridade do texto-fonte, é percebido na manutenção de nomes próprios e de lugares, e de termos que fazem referência ao contexto cultural da narrativa. Esse deslocamento coloca, mais uma vez, a perspectiva da estrangeirização como primeira opção de Miller, como ele mesmo 
afirmou: "Eu não me recordo de muitas situações específicas, nas quais eu senti a necessidade de 'americanizar' a história”25 (Tradução nossa).

Por meio deste estudo, comprovamos que a dicotomia estrangeirização $\mathrm{x}$ domesticação é problemática e polêmica. Considerando a complexidade envolvida em cada processo tradutório, o tradutor tem a difícil tarefa de considerar as diferentes estratégias de tradução e escolher aquela ou aquelas que melhor se adequam ao contexto da tradução. Vale lembrar que toda tradução é subjetiva, pois depende da interpretação do tradutor que também é leitor. Essa consideração nos leva a crer que é impossível optar por uma tradução totalmente estrangeirizante ou apenas domesticadora. Assim como em outras dicotomias, essas estratégias não são estanques, podendo haver diferentes combinações de ambas na tradução de um mesmo texto, como aconteceu na tradução de Uma vida em segredo, além de estratégias híbridas ou soluções que não representam nem uma nem outra posição.

A pesquisa que deu origem a este artigo é no âmbito da literatura comparada e, por isso, precisamos ter em mente a questão da interpretação do texto-fonte pelo tradutor e a recepção desse texto pelo leitor. No caso estudado, entendemos que se o leitor americano não tem conhecimento prévio de aspectos culturais muito específicos de uma cidade do interior mineiro, provavelmente, a escolha do tradutor pela não tradução desses aspectos pode causar estranhamento no leitor de $A$ hidden life. Assim, ao respeitar a alteridade da novela, o tradutor acaba por não respeitar a alteridade do seu leitor, além da possibilidade de influenciar a imagem que o leitor faz da cultura alheia. Isso comprova que o papel do tradutor literário é de fundamental importância, tanto para a cultura de seu próprio país, quanto para a cultura do país ao qual pertence o autor do texto-fonte.

No entanto, não há como servir a dois senhores. Parafraseando Berman (2002), traduzir é trair. Trai-se o nacional ou trai-se o estrangeiro. Mas traduzir também é interpretar, cabendo ao tradutor a decisão de escolher a quem ser fiel.

25 I don't remember too many specific instances of feeling the need to "Americanize" the story (MILLER, 2018). 


\section{REFERÊNCIAS}

AIXELÁ, Javier Franco. Culture-specific items in translation. Tradução de Mayara Matsu Marinho e Roseni Silva. In: VIDAL, C.; ÁLVAREZ, R. (ed.). Translation, power, subversion. Clevendon: Multilingual Matters, 1996. p. 52-78. Traduções, v. 5, n. 8, Florianópolis, 2013, p. 185-218. Disponível em: <http://incubadora.periodicos.ufsc.br/index.php/intraducoes/article/viewFile/2 119/2996>. Acesso em: 5 ago. 2018.

BASSNETT, Susan. Translation Studies. 3. ed. New York: Routledge, 2002.

BERMAN, Antoine. A tradução e a letra ou o albergue do longínquo. Trad. de Marie-Hélène Catherine Torres; Mauri Furlan e Andréia Guerini. Rio de Janeiro: 7letras, 2007.

BERMAN, Antoine. A prova do estrangeiro. Trad. de Maria Emília Pereira Chanut. Bauru: EDUSC, 2002.

BRITTO, Paulo Henriques. O tradutor como mediador cultural. Synergies Brésil, n. spécial 2, São Paulo, 2010, p. 135-141. Disponível em:

<https://gerflint.fr/Base/Bresil_special2/britto.pdf>. Acesso em: 14 mar. 2018.

CAMPOS, Haroldo. Da tradução como criação e como crítica. In:

Metalinguagem e outras metas. 4. ed. São Paulo, Perspectiva, 2006. p. 31-48.

COSTA, Claudia de Lima. Feminismo e tradução cultural: sobre a colonialidade do gênero e a descolonização do saber. Portuguese cultural studies, n. 4, 2012, p. 41-65. Disponível em:

<http://www2.let.uu.nl/solis/PSC/P/PVOLUMEFOUR/PVOLUMEFOURPAPERS/P 4DELIMACOSTA.pdf $>$. Acesso em: 6 jun. 2018.

DOURADO, Autran. Uma vida em segredo (1964). Rio de Janeiro: Rocco, 2010.

DOURADO, Autran. A hidden life. Tradução de Edgar H. Miller Jr. New York: Alfred A. Knopf, 1969.

ISER, Wolfgang. On Translatability. Surface, v. 4, 1996, p. 9-13. Disponível em: <https://www.pum.umontreal.ca/revues/surfaces/vol4/iser.html>. Acesso em: 30 jul. 2018.

MILLER, Edgar H. Knoxville, USA, 16 ago. 2016. Entrevista concedida a Daniela de Azevedo. 
NASCIMENTO, Evandro. A monolíngua: tradução, memória e cultura. In: VOLOBUEF, Karin; TRUSEN, Sylvia Maria; SARMENTO-PANTOJA, Tania. Tradução, cultura e memória. 1. ed. Rio de Janeiro: 7Letras, 2014. p. 111-122.

NORD, Christiane. Translating as a purposeful activity: a prospective approach. TEFLIN Journal, v. 17, n. 2, August, 2006, p. 131-143.

SCHAFER, R. Murray. A afinação do mundo. Tradução de Marisa Trench Fonterrada (1997). São Paulo: Editora Unesp, 1977. p. 33-85.

SCHLEIERMACHER, Friedrich Daniel Ernst. Sobre os diferentes métodos de tradução. Trad. de Celso R. Braida. In: HEIDERMANN, Werner (org.). Clássicos da teoria da tradução: antologia bilíngue, alemão-português. 2. ed. v. 1. Florianópolis: UFSC/Núcleo de Pesquisas em Literatura e Tradução, 2010. p. 38-101.

STEINER, George. After Babel: aspects of language and translation. New York: Oxford University Press, 1975.

VENUTI, Lawrence. The translator's invisibility: a history of translation (1995). London, New York: Routledge, 2004.

\section{Biografia dos autores}

Daniela de Azevedo é especialista em Línguas Estrangeiras Modernas e mestre em Estudos Literários pela Universidade Estadual de Montes Claros - Unimontes. Professora do curso de Letras Inglês da mesma universidade e pesquisadora nas áreas de letramento literário, literatura comparada e tradução.

Osmar Pereira Oliva é mestre em Literatura Brasileira e doutor em Literatura Comparada, pela UFMG. Atua no Mestrado em Estudos Literários da Universidade Estadual de Montes Claros - Unimontes, com pesquisas e publicações sobre gênero, identidade, literatura brasileira contemporânea de autoria feminina. Também se dedica à produção literária de Autran Dourado e seus arquivos, organizados no Arquivo de Escritores Mineiros, da UFMG. 